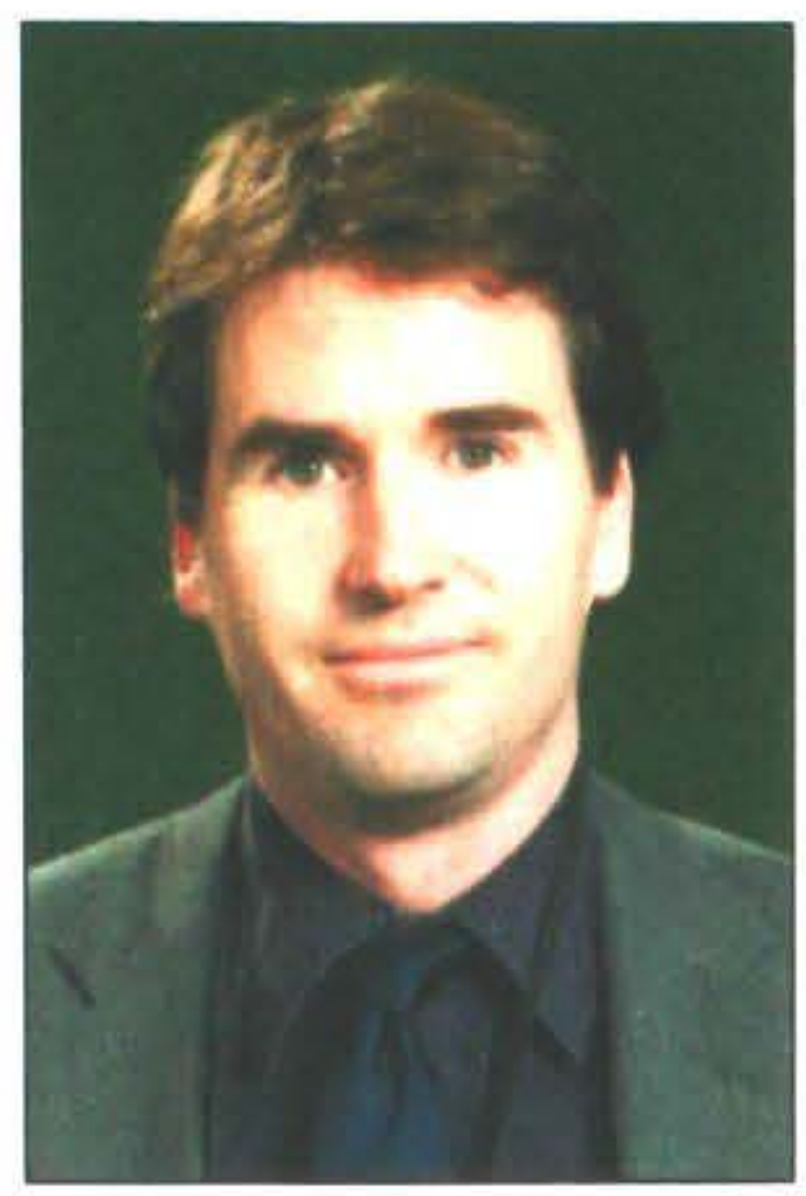

\title{
MEASURING THE NEW ZEALAND KNOWLEDGE ECONOMY
}

\author{
Dean Rutherford
}

Work Directions

Department of Labour, Wellington

\begin{abstract}
This paper provides estimates of the "knowledge economy" for New Zealand using the Population Census. Although the meaning of knowledge economy may differ slightly depending on the context, it is reasonable to say that it refers to the influence of differently skilled individuals on performance of an area, be it social, economic or developmental. Two overseas methodologies were reviewed and applied to the New Zealand context. This paper presents initial findings at a regional and sub-regional level and goes on to consider areas of future development.
\end{abstract}

\section{Introduction}

The 'Knowledge Economy' is a term that has been used widely both in New Zealand and internationally.

The United Nations notes that Knowledge Economy is not an agreed term "... it must be said that there is no coherent definition, let alone theoretical concept, of this term: it is at best a widely used metaphor, rather than a concept."

The term "knowledge based economy" was coined by the OECD and defined as an economy which is "directly based on the production, distribution and use of knowledge and information"2 (OECD 1996).

While the meaning of 'knowledge economy' may differ slightly depending on the context, it is reasonable to say that the term refers to the influence of differently skilled individuals on performance of an area, be it social, economic or developmental performance. It is commonly reported that highly skilled people add more on average per person to the development and performance of an economy. While it is recognised that having all workers of an economy being highly skilled is not practical or even desired, most if not all OECD countries are attempting to raise average skill levels of their workers.

\section{Background}

Measurement of the Knowledge Economy is important to the Department of Labour (DoL). In the current environment of low unemployment rates and high labour force participation, further development of the labour force is most likely achieved through skill enhancement of existing members of the labour force. The measurement of skills is therefore important in the understanding the characteristics of the current labour market. Without an idea of the current level of labour market skills across industries, occupations and regions, processes which target the improvement in skills would be inefficient if not misdirected.

The Department of Labour makes frequent reference to the importance of Productivity improvements. On the Introduction page of the DoL website it says that the role of DoL is to "support regions and industries and employers to develop a skilled, innovative and productive workforce ${ }^{* 3}$. Productivity improvements are vital for New Zealand. If the New Zealand economy is to grow, increasingly this will be dependent on productivity improvements. With the pool of extra workers (generally unemployment) more or less absorbed into employment over the last 5 years, the growth in output will need to come from improvements in output per worker hour (Productivity).

It is generally agreed that increased levels of knowledge, via formal training or on the job development increases the productivity of those workers. Highly productive workplaces are a particular focus of the DoL report, 'Better Work, Working Better".

By improving skill levels of New Zealand employees, the jobs of these employees also become decreasingly susceptible to replacement by lower wage economies. The measurement of knowledge and the change in the stocks of that knowledge are central to the development of desired levels of worker productivity and job security. 


\section{Methodologies Used}

While the theoretical concepts involved in Knowledge economies are important, for the concepts to be applied it is also important to have a definition that is able to be measured. This drive towards application and measurement can be seen internationally.

Amongst other international institutions, The World Bank has developed the 'Knowledge Assessment Methodology', and a variety of other agencies including the OECD have noted the importance of Research and Development (R\&D) spend, Academic research and the number of Patents issued as indicators of knowledge intensity. Recently in Australia ${ }^{6}$, the overemphasis on measurement of R\&D expenditure has been criticised. The Australian Business Foundation report notes that the contribution of 'non research and development' components of the innovation process "such as engineering experimentation, skill development, design activities $^{\prime \prime}$ should not be underestimated. By assigning the responsibility for innovation growth to $R \& D$ processes, the costs of innovation are under estimated, and the returns to R\&D spend are overestimated.

Two relatively recent examples of the drive to produce actual measurements of knowledge intensity come from the United Kingdom based organisations, Local Futures ${ }^{8}$, and The Work Foundation?

Local Futures bases their measurement of the Knowledge Economy on educational qualifications as a proxy for knowledge. Local Futures calculate the Knowledge Intensity of an Industry or an Occupation based upon the proportion of the relevant workforce that has University degrees or Higher.

As part of their methodology Local Futures developed a Knowledge rating scale, as displayed in Table 1. The higher the proportion of employees in an industry with a university graduate or higher qualification, the more knowledge intensive the industries were considered to be. For example where an industry has $40 \%$ or more of its employees with a University qualification, this industry is considered to be particularly knowledge intensive, and assigned the highest rating, at $\mathrm{K} 1$.

\section{Table 1: Local Futures Knowledge Intensity groupings}

\begin{tabular}{|l|l|l|}
\hline Lower share & Upper share & Rating \\
\hline 0.00 & 0.15 & $\mathrm{~K} 4$ \\
\hline 0.15 & 0.25 & $\mathrm{~K} 3$ \\
\hline 0.25 & 0.40 & $\mathrm{~K} 2$ \\
\hline 0.40 & 1.00 & $\mathrm{~K} 1$ \\
\hline
\end{tabular}

The Work Foundation bases their calculation of the Knowledge Economy using the proportion of occupation types within a labour force. The Knowledge Intensity of an area (industry, region, sector) is determined by the proportion of the workforce who are employed as Legislators, Administrators and Managers, Professionals or Technicians and Associated Professionals. A high share of these occupations within a labour force is interpreted as being Knowledge Intensive, while a low share of these occupations within a labour force is interpreted as having low knowledge intensity.

These three occupation groups are identified by The Work Foundation as those with the consistently highest stocks of knowledge. The proportion of these occupations within an industry or region provides an indicator of the skills available. This assignation of high skills to these three occupational groupings is based upon an internationally followed categorisation of occupations, something also obserrved in New Zealand.

By defining a measure for knowledge in an economy, both methodologies allow the analyst to apply these calculations to a range of other variables. For example, knowing the highest qualification of a range of people (say in a region) as well as their age and industry of employment, using the Local Futures methodology you can analyse how knowledge intensity in different industries change as the workers age. The Work Foundation methodology is similar. For example, knowing how many workers are in each occupation group along with their duration of time spent in New Zealand, using The Work Foundation methodology you can analyse how knowledge intensity in migrants changes as their length of stay in New Zealand increases.

Commonly stated objections to the application of these methodologies include a) possession of a tertiary qualification not necessarily being linked to knowledge work, and b) Knowledge worker occupations being subjectively measured and again not necessarily reflecting knowledge work. While there are assumptions within both methodologies that can be challenged, some element of pragmatism is required to define a measure that can be calculated and tracked over time.

As part of the review of the methodologies used by Local Futures and The Work Foundation, a paper using each methodology was chosen for replication. By replicating the calculations, it was possible to determine whether the datasets were available in New Zealand to conduct the work. Additionally, the application to a New Zealand setting made it possible to review the assumptions and categorisations made in a practical setting.

The two papers that have been chosen are 'Understanding the Knowledge Economy' ${ }^{10}$ and "Ideopolis: Knowledge City-Regions" "'. 'Understanding the Knowledge Economy' is a conference paper which uses the Local Futures measurement methodology, while the 'Ideopolis' paper is written by The Work Foundation, and uses the Work Foundation measurement methodology. Both of these papers have been selected based on the relatively introductory nature of the 
measurement methodology - reflecting the initial stage of this project within the Department of Labour.

Within New Zealand there are a range of datasets that produce labour market information. After reviewing the datasets (including the Household Labour Force Survey, Income Survey, Linked Employer Employee dataset and the Business Demography Survey) only the Population Census included the range of measured variables and quality of detailed data required to produce the calculations required.

The Population Census dataset combines the dual benefits of variety of questions, and the full coverage collection required for this analysis. The two international methodologies reviewed analyse knowledge stocks across a range of variables, as well as at a particularly detailed geographical level. The Population Census is the only New Zealand dataset able to generate multiple and disaggregated variables (be it detailed industry codes or detailed geographic breakdowns).

Once the two methodologies were identified, the next step was to apply these methodologies in a New Zealand context. By applying these methodologies, an initial view of knowledge stocks within New Zealand could be developed.

Part of the value of measuring knowledge stocks is to identify how levels vary across different disaggregations, especially on a sub national basis. By showing how knowledge intensity varied across the United Kingdom, both papers provide interesting sub national content, able to be used by local level strategic decision makers.

While Regional Council data does show noticeable differences in knowledge intensity, we found that the real value of these analyses is at the TA level. In the process of reviewing and applying the two methodologies, the calculations of the two chosen papers were replicated at both a regional council and $\mathrm{TA}$ basis.

At each extra level of industry disaggregation, a more complete story can be read. The initial dataset made available to DoL was at the one digit industry and occupation level. One digit industry data showed very few regional highly knowledge intensive industries, with the majority of results showing low knowledge intensity. As data at a 2 digit and 3 digit levels became available, noticeable differences in regional industry composition became more apparent. When disaggregated Industry or Occupation data is combined with disaggregated geographical data (TA results) a much wider range of knowledge intensity is shown.

While the methodologies of both Local Futures and The Work Foundation focus on slightly different indicators to determine the level of knowledge intensity, the results are quite similar.
When data is analysed at a Regional Council level, there are no areas which qualify as being highly Knowledge Intensive under the most basic evaluations of either methodology. Within New Zealand, each of the largest regions of New Zealand has a combination of strongly urban and strongly rural areas. It is this diversity that has meant that any knowledge intensity that does exist within a region is dispersed due to the lack of knowledge intensity elsewhere. By breaking the geographic data down further, to the TA level, consistent areas (fully urban or fully rural are produced.

The analysis of results focuses on identifying the location of high levels of knowledge intensity. Locations of high levels of knowledge intensity help identify where programmes can be implemented which depend on high knowledge stocks (this is the idea behind Knowledge centres or knowledge economies). Equally important, although not addressed directly in this research, is the identification of lower levels of knowledge. This information could be used to a) identify whether this lower stock is a concern, and if it is to b) develop programmes to increase knowledge intensity.

\section{Research findings}

At a TA level, results for Wellington City and Auckland City clearly stand out from the remainder of the cities and districts of New Zealand as the most concentrated stores of knowledge. Across each of the calculations of both the Local Futures and The Work Foundation methodologies, Wellington and Auckland cities consistently show the highest levels of Knowledge Intensity.

Throughout the analysis, Wellington and Auckland rated highest in the majority of calculations.

1. They are the TAs with the largest proportion of high knowledge industries.

2. They have the largest growth in this proportion between 2001 and 2006 .

3. The public sector employment of the two TA's has the highest proportion of graduates.

4. The private sector employment of the two TA's has some of the fastest increase between 2001 and 2006.

5. They are the only two TAs with a share of graduates greater than their share of the working age population (a high concentration of graduates).

6. They have the highest share of knowledge workers in both 2001 and 2006

7. They have the highest share of knowledge intensive business units in both 2001 and 2006. 
8. They have the highest share of employment in knowledge intensive industries in both 2001 and 2006.

9. Auckland and Wellington regions also have the highest shares of employment of knowledge intensive occupations in knowledge intensive industries.

The main difference between the results for Wellington and Auckland cities is the difference of sector of employment. The public sector employed $39.7 \%$ of all degree holders in Wellington City, while the equivalent figure for Auckland City was only $26.8 \%$. The share of Auckland City degree holders in public sector employment is particularly low, with only Queenstown Lakes District being lower.

This low result for Auckland City reflects the large volume of high knowledge employment in the Auckland Private sector. Auckland City employment is characterised by a combination of a smaller share of government industry and higher share of private sector employment in industries like Finance and Insurance, and Property and Business Services.

Outside of Auckland and Wellington cities, Public sector employment of tertiary graduates is more prominent. Sixteen TA's in 2006 had more than half of their resident tertiary graduates employed in the Public sector. Of these sixteen TA's, the majority were smaller, rural and relatively isolated districts. Kawerau District had the highest share of public sector employment of graduates with $85.7 \%$ of graduates employed by government agencies.

\section{Implications of results}

The initial purpose of this investigation was to identify whether Knowledge Economy calculations as conducted elsewhere were feasible with New Zealand datasets. Of the two methodologies reviewed, all but one of the calculations required has been produced from data currently available. These calculations provide results that indicate the location and scale of the knowledge economy within New Zealand. The only calculation not currently able to be replicated is the analysis of knowledge intensity of employees by business size.

While the data is available to measure the New Zealand Knowledge Economy, the vast majority of the data comes from the Population Census. Given the timing of the conduction of the Census, this analysis will only be able to be updated every five years. While development of new knowledge may leap from discovery to discovery, the methodologies used here measure the dissemination of knowledge across the wider labour force - something that does not change significantly on an annual basis. Given the relatively slow rate of change, 5 yearly updates of these calculations are likely to be satisfactory.
The overriding result from this paper is the focus of knowledge workers and knowledge industries within Auckland and Wellington cities. As shown in the Research findings section, Wellington and Auckland cities generally have the strongest results across almost all of the calculations conducted.

The consistency of the results produced by this analysis shows that it is currently only Wellington and Auckland Cities that could currently be considered to be heading towards a 'knowledge economy' status. The importance of this finding is that if an industry is looking to locate to a site where widespread knowledge intensity is available, it is Wellington and Auckland that provide the most complete state available in New Zealand. On a partial basis several other TA's provide some of the knowledge environment, these TA's include (in no particular order) North Shore City, Christchurch City, Palmerston North City, Hamilton City and Dunedin City. Some of these locations already market their ability to be a source of highly educated staff.

The concentration of graduate employment in the public sector outside of Auckland and Wellington limits the potential for growth in knowledge stocks. For graduate employment to continue or to expand within these districts, dependence upon government agencies needs to decline. It cannot be expected that public sector employment will continue to grow to provide more regional vacancies for graduates. The focus of growth needs to come from private sector employment.

While the majority of New Zealand employment is in lower skilled industries, skill levels are increasing over time (this pattern is shown using both of the methodologies replicated). Consistently across the country and across industries, skill levels were higher in 2006 than they were in 2001. This pattern of increased skill levels is noted in each of the Annual In Depth Regional reports ${ }^{12}$ as well as the inter temporal analysis of this report.

It would appear that knowledge intensity in New Zealand is at a lower level than in the United Kingdom. With the exception of Auckland and Wellington cities, New Zealand based calculations produce lower results at both a region and TA level than for equivalent areas in the United Kingdom based reports. This result is especially significant as UK data is generally from 2001 while New Zealand data is for 2006 - the United Kingdom knowledge intensity is likely to be higher in 2006 data. The validity of a direct comparison of results between New Zealand and other countries will be considered as part of Phase Two of the Knowledge Economy project.

Results for Canterbury are consistently stronger under The Work Foundation methodology. This suggests that Canterbury has a slightly stronger focus on Knowledge Industries compared with highly skilled workers within those industries. Having said this, Canterbury and 
Christchurch in particular shows relatively strong results in both methodologies.

\section{Future work}

While the work done so far has focussed on replicating the initial findings of the Local Futures and Work Foundation documents, both of these organisations have now evolved their measurement methods much further.

The next stage of the Knowledge Economy project will be for the investigation and potential replication of current Knowledge Economy methodologies. While there will be a particular focus of Local Futures and The Work Foundation, other sources of analysis will also be considered.

The next stage will also include a review of the methodologies with a view to the customising of measures for a New Zealand environment. The impact of changing methods will be evaluated and 'New Zealand' solutions will be considered.

Given the insights available from the inter temporal analysis, the next stage will also include an extension of the time series. Statistics New Zealand will be contacted to provide 3 digit 1996 and 1991 Population Census data based on an ANZSIC 96 and NZSCO99 basis.

The vast majority of analysis has come from data based on the Usual residence of the Population Census respondent, rather than on a Workplace basis. Data on a 'Usual Residence' basis is much cleaner (there is less non response error) however data based on Workplace may be more meaningful. The next analysis will consider the replication of this work on a Workplace basis rather than a Usual Residence basis.

Wider stakeholder engagement will occur as part of the next stage of the Project. In particular, the Ministry of Economic Development (MED) and New Zealand Trade and Enterprise (NZTE) and internally colleagues will be approached to provide input into the design of any methodology developed in the second phase of the project.

\section{Notes}

1. "What is the Knowledge Economy? Knowledge Intensity and Distributed Knowledge Bases" Keith Smith, United Nations University, June 2002

2. "The Knowledge Based Economy", OECD, OCED/GD(96)102. Pg 7 . www.oecd.org/dataoecd/51/8/1913021.pdf

3. http://www.dol.govt.nz/about/index.asp
Pg 9, Better Work, Working Better, Labour Market \& Employment Strategy, Department of Labour New Zealand

5. http://www.worldbank.org/kam

6. "Innovation and the Knowledge Economy in Australia", Australian Business Foundation, May 2006

7. Ibid, $\mathrm{Pg} 18$

8. http://www.localfutures.com/

9. http://www.theworkfoundation.com/index.aspx

10. 'Understanding the Knowledge Economy - From Theory to Practice', National RDA Research Conference paper, March 2004

11. 'Ideopolis: Knowledge City - Regions'. The Work Foundation, March 2006.

12. These reports, published by the Department of Labour investigate labour market characteristics of the 12 regional council areas of New Zealand. These reports are available on the Department of Labour website.

\section{References}

Australian Business Foundation (2006). Innovation and the Knowledge Economy in Australia.

Lawton, C. and Davies, D. (2004). Understanding the Knowledge Economy - From Theory to Practice, National RDA Research Conference paper.

Smith, K. (2002). What is the Knowledge Economy? Knowledge Intensity and Distributed Knowledge Bases, United Nations University.

The Work Foundation (2006). Ideopolis: Knowledge City - Regions

\section{Author}

Dean Rutherford

Labour Market Analysis

Work Directions

Department of Labour

P.O. Box 3705

Wellington

Dean.Rutherford@dol.govt.nz 